\title{
Increased calcium intake was associated with decreased risk of ischaemic heart disease mortality in postmenopausal women
}

Bostick RM, Kushi LH, Wu Y, et al. Relation of calcium, vitamin D, and dairy food intake to ischemic heart disease mortality among postmenopausal women. Am J Epidemiol 1999 Jan 15;149:151-61.

\section{Question}

Is intake of calcium, vitamin $\mathrm{D}$, or milk products associated with ischaemic heart disease (IHD) mortality in postmenopausal women?

\section{Design}

Prospective cohort study of women in the Iowa Women's Health Study with 8 years of follow up.

\section{Setting}

Iowa, USA.

\section{Participants}

34486 women who were 55-69 years of age. Women were excluded if they had IHD at baseline, were premenopausal, did not complete $\geq 30$ items on the food frequency questionnaire, or had implausibly high or low daily energy intake scores.

\section{Assessment of risk factors}

Women completed postal questionnaires on known and suspected risk factors for cardiovascular disease in 1986. A 127 item semiquantitative food frequency questionnaire measured usual food intake and vitamin and mineral supplement use. For analysis, women were divided into quartiles based on intake of food, nutrients, and other characteristics.

\section{Main outcome measure}

Death from IHD (1986-94) obtained from questionnaires and state and national databases.

\section{Main results}

During follow up, 387 deaths from IHD occurred (57\% from acute myocardial infarction, 30\% from chronic IHD, and 13\% from arteriosclerotic cardiovascular disease). Multivariate analy- sis showed that total calcium intake was associated with IHD mortality. Compared with women in the lowest quartile of total calcium intake, those in the second and fourth quartiles had reduced risks of IHD mortality, but those in the third quartile did not (table). A daily intake of $1-500 \mathrm{mg}$ of supplemental calcium was also associated with a reduced risk of IHD (relative risk 0.76 , $95 \%$ CI 0.58 to 1.00 ). Dietary calcium; total, dietary, and supplemental vitamin $\mathrm{D}$; and total and fat containing dairy intake were not associated with IHD mortality.

\section{Conclusion}

A higher intake of total calcium, but not vitamin D or dairy products, was associated with a decreased risk of ischaemic heart disease mortality in postmenopausal women.

Relative risks for death from ischaemic heart disease for quartiles of total calcium intake in women*

\begin{tabular}{llll}
\hline Quartile & $\begin{array}{l}\text { Number of } \\
\text { women }\end{array}$ & Total calcium intake & Relative risk $(95 \%$ CI $)$ \\
\hline First & 127 & $<696 \mathrm{mg} / \mathrm{day}$ & 1.00 \\
Second & 84 & $696-1051 \mathrm{mg} /$ day & $0.62(0.45$ to 0.85$)$ \\
Third & 94 & $1052-1425 \mathrm{mg} /$ day & $0.75(0.55$ to 1.03$) \dagger$ \\
Fourth & 82 & $1425 \mathrm{mg} / \mathrm{day}$ & $0.67(0.47$ to 0.94$)$ \\
\hline
\end{tabular}

*Abbreviations defined in glossary. Analyses adjusted for age, total energy intake, body mass index, waist to hip ratio, history of diabetes mellitus, smoking status, postmenopausal oestrogen use, alcohol intake, education, marital status, physical activity, dietary vitamin $\mathrm{E}$ intake, and saturated fat intake. †Not significant.

\section{Source of funding: National Cancer Institute.}

For correspondence:Dr R M Bostick, Division of Population Sciences, South Carolina Cancer Center, University of South Carolina, 15 Richland Medical Park, Suite 301, Columbia, SC 29203, USA. Fax +18034347529 .

\section{Commentary}

The results of Bostick et al suggest that among postmenopausal women, the risk of dying of IHD may be reduced by consuming relatively high concentrations of calcium. This association seems plausible given the findings of previous research showing that higher consumption of calcium lowers blood cholesterol concentrations, ${ }^{1}$ may reduce blood pressure, ${ }^{2}$ and may prevent hypertension.

The strengths of this study are that it was prospective and included a large, well defined cohort derived from a general population. In addition, the validity of the nutritional questionnaire is impressive and well supported by published data. The limitations of the study are the many confounders related to the evaluation of the effects of vitamins and minerals on health or disease states. Data on possible confounders, such as sunlight exposure as a source of vitamin $\mathrm{D}$, were not provided.

The findings suggest that there is no increase in IHD mortality as a result of increased calcium intake, provided the calcium does not come from fat containing milk products. Furthermore, the findings are consistent with a $30-35 \%$ reduction in IHD mortality among postmenopausal women with a high intake of calcium. More studies are needed to substantiate these findings and to clarify practice recommendations, particularly in relation to the non-significant results for the third quartile of calcium intake. Diet and vitamin supplementation should be one of a broader spectrum of lifestyle factors considered for health promotion, disease prevention, and treatment. Studies continue to report that people who have healthy eating habits, exercise more frequently, and do not smoke have better health outcomes. ${ }^{3}{ }^{4}$

\section{Vaska Micevski, RN, ACNP, MScN Acute Care Nurse Practitioner Cardiac Program Toronto Western Hospital University Health Network Toronto, Ontario, Canada}

1 Bell L, Halstenson CE, Halstenson CJ, et al. Cholesterol-lowering effects of calcium carbonate in patients with mild to moderate hypercholesterolemia. Arch Intern Med 1992;152:2441-4

2 Allender PS, Cutler JA, Follmann D, et al. Dietary calcium and blood pressure: a metaanalysis of randomized clinical trials. Ann Intern Med 1996;124:825-31.

3 Hu FB, Stampfer MJ, Manson JE, et al. Frequent nut consumption and risk of coronary heart disease in women: prospective cohort study. BMJ 1998;317:1341-5.

4 Fraser GE, Shavlik DJ. Risk factors for all-cause and coronary heart disease mortality in the oldest-old. The adventist health study. Arch Intern Med 1997;157:2249-58. 